\title{
A GARANTIA DA MOTIVAÇÃO DAS DECISÕES JUDICIAIS À LUZ DO DIREITO AO PROCESSO JUSTO E DA JURISPRUDÊNCIA DA CORTE EUROPEIA DE DIREITOS HUMANOS ${ }^{1}$
}

\section{THE DUTY TO GIVE REASONS AS A GUARANTEE FOR A FAIR TRIAL UNDER THE SIGHT OF THE EUROPEAN COURT OF HUMAN RIGHTS}

\section{Marcella Alves Mascarenhas Nardelli} Doutoranda em Direito Processual pela UERJ. Mestre em Direito pela Faculdade de Direito de Campos/RJ. Professora Assistente de Direito Processual Penal da Universidade Federal de Juiz de Fora/MG (UFJF). marcellamascarenhas@hotmail.com

RESUMO: O presente trabalho pretende definir os contornos da garantia da motivação das decisões judiciais em seu aspecto teórico - segundo a doutrina processual contemporânea -, bem como evidenciar sua importância para a concretização de um processo justo. Paralelamente, a motivação será analisada em uma perspectiva prática segundo a jurisprudência consolidada da Corte Europeia de Direitos Humanos, com especial enfoque para o caso Taxquet c. Bélgica e suas repercussões sobre os Tribunais de Júri.

PALAVRAS-CHAVE: Motivação das Decisões Judiciais; Processo Justo; Convenção Europeia de Direitos Humanos; Tribunal do Júri.

\begin{abstract}
This paper aims to define the outlines of the judicial duty to provide reasons for their decisions in its theoretical aspect - according to contemporary procedural knowledge -, as well as to establish its importance for the concretion of a fair trial. At the same time, the duty to give reasons will be analyzed in a practical
\end{abstract}

\footnotetext{
${ }^{1}$ Artigo recebido em 23/04/2015 e aprovado em 21/06/2015.
} 
Revista Eletrônica de Direito Processual - REDP. Volume 15. Janeiro a Junho de 2015

Periódico Semestral da Pós-Graduação Stricto Sensu em Direito Processual da UERJ.

Patrono: José Carlos Barbosa Moreira. www.redp.com.br ISSN 1982-7636 PP 349-376

perspective according to the case-law of the European Court of Human Rights, with a special emphasis in the case Taxquet v. Belgium and its impact on Jury Trials.

KEYWORDS: Judicial duty to give reasons; Fair Trial; European Convention of Human Rights; Trial by Jury.

SUMÁRIO: Introdução. 1. O Processo Justo. 2. A Garantia da Motivação das Decisões Judiciais. 3. A Garantia da Motivação à luz da Jurisprudência da Corte Europeia de Direitos Humanos. 3.1. A Corte Europeia de Direitos Humanos e o Caso Taxquet v. Bélgica. Considerações Finais. Referências Bibliográficas.

\section{INTRODUÇÃO}

A adequada reconstrução dos fatos no processo é fator condicionante para uma decisão justa e por tal motivo as disposições relativas à prova e sua consequente valoração pelo juiz são objeto de estudos nos sistemas processuais modernos, mormente no que tange a um eventual controle dessa atividade cognitiva do juiz.

O procedimento probatório, em seu conjunto, engloba diferentes fases que vão desde a postulação e consequente admissão, passando pela efetiva produção e culminando com a valoração das provas $^{2}$, esse, sem dúvida, o momento mais relevante, vez que nele se concentra todo o resultado da atividade probatória.

Faz-se necessária a análise de como ocorre a fiscalização dessa atividade de cognição e valoração desempenhada pelo juiz em relação às provas constantes no processo e a necessidade de motivação das decisões judiciais se mostra relevante nesse intuito $^{3}$.

\footnotetext{
${ }^{2}$ Ovídio Batista da Silva destaca três momentos da atividade probatória: aquele em que a prova é proposta, aquele em que é admitida pelo juiz e aquele em que é produzida. SILVA, Ovídio A. Batista da. Curso de Processo Civil. 3. ed. Porto Alegre: Fabris, 1996, p. 292. Barbosa Moreira ressalta três em que há o relacionamento do juiz com a prova: fase da determinação da prova; fase da realização da prova e fase da valoração da prova. BARBOSA MOREIRA, José Carlos. O Juiz e a Prova. . In: Revista de Processo. São Paulo, n. 35, p. 178-184, abril/junho de 1984, p. 178.

${ }^{3}$ Para Barbosa Moreira, a cognição e a motivação são bases de um Estado de Direito. Segundo ele, " $a$ justificativa material está na existência do fundamento e a formal, na exposição, declaração e demonstração do fundamento. Extrai essa colocação da caracterização do Estado de Direito como Estado que justifica." BARBOSA MOREIRA, José Carlos. A motivação das decisões judiciais como garantia inerente ao estado de direito. In: Temas de Direito Processual. 2. ed. São Paulo: Saraiva, 1988, p. 83.
} 
Revista Eletrônica de Direito Processual - REDP. Volume 15. Janeiro a Junho de 2015 Periódico Semestral da Pós-Graduação Stricto Sensu em Direito Processual da UERJ. Patrono: José Carlos Barbosa Moreira. www.redp.com.br ISSN 1982-7636 PP 349-376

Cumpre destacar que a valoração da prova e a motivação das decisões judiciais estão relacionadas, na medida em que é através da última que se torna possível verificar os critérios utilizados pelo juiz na análise do material probatório, evitando-se o arbítrio. Também se relaciona com a motivação o princípio do contraditório, pois para que haja uma aceitabilidade da decisão, esta deve se fundar em argumentos jurídicos decorrentes do contraditório entre as partes. ${ }^{4}$ A motivação deve deixar expresso que houve a valoração equitativa das provas produzidas por ambas as partes, contendo a razão pelo desprezo de umas em função de outras mais convincentes.

A utilização de critérios racionais nas decisões judiciais, através de uma fiel valoração das provas e de uma motivação lógica e coerente é pressuposto de uma decisão justa. O livre convencimento motivado ou persuasão racional, como sistema de avaliação probatória, tem como objetivo fundamental garantir essa justiça da decisão, proporcionando a todos um controle sobre o ato decisório através de uma análise criteriosa da fundamentação.

Ciente do importante papel desempenhado pela motivação das decisões judiciais à luz do direito a um processo equitativo, importante analisar os contornos da garantia na visão da doutrina e da jurisprudência da Corte Europeia de Direitos Humanos, esta última responsável por estabelecer os padrões mínimos exigidos para o seu atendimento por parte da Comunidade Europeia.

Paralelamente, verifica-se que ainda é marcante em alguns sistemas a presença da instituição do júri popular que, embora possa admitir configurações internas distintas, normalmente tem seus vereditos imotivados. É fato notório que o papel desempenhado pelo júri é de grande relevância e envolve importância histórica, simbólica, política e ritualística, o que não se questiona. $\mathrm{O}$ que deve ser levado em consideração é se, em um Estado Democrático de Direito, que possui como um dos pilares a dignidade da pessoa humana e organiza seu sistema processual de acordo com as garantias fundamentais do processo, pode subsistir de forma inquestionável tal

\footnotetext{
${ }^{4}$ Interessantes as considerações realizadas por Ronaldo Brêtas de Carvalho Dias e Débora Carvalho Fioratto sobre a conexão entre contraditório e fundamentação das decisões. No mesmo sentido, Flaviane Magalhães Barros: "(...) a fundamentação da decisão é indissociável do contraditório, visto que garantir a participação dos afetados na construção do provimento, base da compreensão do contraditório, só será plenamente garantida se a referida decisão apresentar em sua fundamentação a argumentação dos respectivos afetados, que podem, justamente pela fundamentação, fiscalizar o respeito ao contraditório e garantir a aceitabilidade racional da decisão." apud. CARVALHO DIAS, Ronaldo Brêtas de; FIORATTO, Débora Carvalho. A Conexão entre os Princípios do Contraditório e da Fundamentação das Decisões na Construção do Estado Democrático de Direito. In: Revista Eletrônica de Direito Processual. Ano 4, Vol. V, Jan./Jun. de 2010, p. 252.
} 
Revista Eletrônica de Direito Processual - REDP. Volume 15. Janeiro a Junho de 2015 Periódico Semestral da Pós-Graduação Stricto Sensu em Direito Processual da UERJ. Patrono: José Carlos Barbosa Moreira. www.redp.com.br ISSN 1982-7636 PP 349-376

sistema que não permite uma avaliação criteriosa da racionalidade de suas decisões. Para tanto, será dado especial enfoque ao caso Taxquet v. Bélgica, no qual a Corte Europeia procurou responder a tais questionamentos.

\section{O Processo Justo}

Ovídio Batista ${ }^{5}$, calcado nas lições de Merryman, assevera que a concepção que se tem da jurisdição é reflexo da influência da configuração jurídica adotada, se de civil law ou common law. Os primeiros concebem a jurisdição como função estatal destinada a tratar de interesses privados, sendo esse caráter privatístico nota peculiar constante na formação das instituições jurídicas da Europa Continental. Nesse sentido, o juiz da civil law assemelha-se mais a um funcionário público do que propriamente representante do poder estatal. Conforme Merryman, o juiz do sistema continental é tratado como mero aplicador da lei, não tendo sido considerado parte de uma atividade criadora, tudo em função da doutrina da estrita separação de poderes. O juiz da civil law desempenha um papel muito mais modesto que seu colega de common law, criativo e soberano.

Desta forma, durante muito tempo se discutiu a Jurisdição com base nas teorias de Chiovenda ${ }^{6}$, pela qual o juiz atua a vontade concreta da lei, sendo, tão somente, la bouche de la loi, e de Carnelutti $^{7}$, para quem ao juiz caberia a justa composição da lide através da criação da norma individual que faz concreta a norma geral. No entanto, nenhuma das teorias responde aos valores do Estado constitucional, a uma porque ambas são escravas do princípio da supremacia da lei, a duas porque negam lugar à compreensão do caso concreto no raciocínio decisório, raciocínio este que leva à prestação jurisdicional. $^{8}$

Em seguida, começa a se mostrar evidente uma tendência na Itália, através de Luigi Paolo Comoglio ${ }^{9}$, e nos Estados Unidos através de Owen Fiss ${ }^{10}$, que consiste em

\footnotetext{
${ }^{5}$ SILVA, Ovídio Batista da. Curso de Processo Civil. Vol. 2. 3. ed. São Paulo: Revista dos Tribunais, 1998, p. 335.

${ }^{6}$ CHIOVENDA, Giuseppe. Instituições de direito processual civil. Campinas: Bookseller. 2000. Vol. I. p.67.

${ }^{7}$ CARNELUTTI, Francesco. Sistema de direito processual civil. $2^{\text {a }}$ Ed. São Paulo: Lemos e Cruz, 2004, vol. I, p. 371

${ }^{8}$ MARINONI, Luiz Guilherme. Teoria Geral do Processo. $2^{\mathrm{a}}$ ed. V. 1. São Paulo: Revista dos Tribunais, 2007, p. 96.

${ }^{9}$ COMOGLIO, Luigi Paolo. Etica e tecnica del "giusto processo". Torino: G. Giappichelli, 2004.

${ }^{10}$ FISS, Owen. Um Novo Processo Civil: Estudos norte-americanos sobre jurisdição, constituição e sociedade. São Paulo: Editora Revista dos Tribunais, 2004.
} 
Revista Eletrônica de Direito Processual - REDP. Volume 15. Janeiro a Junho de 2015 Periódico Semestral da Pós-Graduação Stricto Sensu em Direito Processual da UERJ. Patrono: José Carlos Barbosa Moreira. www.redp.com.br ISSN 1982-7636 PP 349-376 atrelar a jurisdição à aplicação de princípios constitucionais. Segundo essa tendência, o juiz não deve se prender ao que diz a lei e nem, tão somente, em resolver de maneira justa o conflito entre as partes, mas sim aplicar, no caso concreto, os princípios constitucionais. No Estado contemporâneo, a lei tem sua substância condicionada aos princípios constitucionais de justiça e aos direitos fundamentais, por isso, somente se deve admitir as interpretações que a eles estejam adequadas. ${ }^{11}$

A partir da constitucionalização e da internacionalização dos direitos fundamentais, conforme Leonardo $\mathrm{Greco}^{12}$, revelou-se o conteúdo da tutela jurisdicional efetiva como direito fundamental por meio de uma série de regras mínimas, a que se convencionou denominar garantias fundamentais do processo. Essas regras foram universalmente acolhidas em todos os países que instituem a dignidade da pessoa humana como um dos pilares do Estado Democrático de Direito.

Esse conjunto de garantias, cujo conteúdo fora particularmente desenvolvido na jurisprudência dos tribunais constitucionais e das instâncias supranacionais de Direitos Humanos, como a Corte Europeia de Direitos Humanos, pode ser sintetizado nas denominações devido processo legal, adotada nas Emendas $5^{\mathrm{a}}$ e $14^{\mathrm{a}}$ da Constituição americana, ou processo justo, constante da Convenção Europeia de Direitos Humanos e do artigo 111 da Constituição italiana. ${ }^{13}$

No Brasil, seguindo-se a tendência garantista, a Constituição brasileira de 1988 inseriu em seu artigo $5^{\circ}$ as bases para o estabelecimento de um processo justo, onde se encontra, inclusive, a expressa menção ao direito ao devido processo legal. Além disso, vale mencionar o artigo 93, IX, que contempla as garantias da publicidade e da motivação das decisões judiciais. Por fim, completando esse modelo processual, contribuem a Convenção Americana de Direitos Humanos e o Pacto Internacional de Direitos Civis e Políticos, ambos em vigor no Brasil, por seus artigos $8^{\circ}$ e 14, respectivamente, que desenvolvem as regras constantes nos artigos 10 e 11 da Declaração Universal dos Direitos do Homem de 1948, e apresentam conteúdo semelhante ao artigo $6^{\circ}$ da Convenção Europeia de Direitos Humanos.

É certo que o apego irrestrito às garantias fundamentais do processo não necessariamente levará a uma decisão materialmente justa, mas, ao contrário, trará a

\footnotetext{
${ }^{11}$ MARINONI, Luiz Guilherme. op. cit., p. 98.

12 GRECO, Leonardo. Garantias Fundamentais do Processo: O Processo Justo. in Estudos de Direito Processual. Campos dos Goytacazes: Faculdade de Direito de Campos, 2005, págs.225/286.

${ }^{13}$ Idem.
} 
Revista Eletrônica de Direito Processual - REDP. Volume 15. Janeiro a Junho de 2015 Periódico Semestral da Pós-Graduação Stricto Sensu em Direito Processual da UERJ. Patrono: José Carlos Barbosa Moreira. www.redp.com.br ISSN 1982-7636 PP 349-376

segurança jurídica de que a decisão alcançada será legítima. Essa análise leva, inevitavelmente, às discussões sobre a verdade, se ela é ou não um fim do processo e em que medida e sob quais limitações deve ser buscada.

Conforme Taruffo ${ }^{14}$, há ao menos dois tipos de razões pelas quais o conceito de verdade dos fatos no processo é altamente problemático no plano da definição do papel das provas. $\mathrm{O}$ primeiro tipo de razões se refere à contradição entre verdade formal ou processual e verdade material ou real. Essencialmente, se trata de saber se há identidade entre essas concepções. Segundo os juristas, haveria, de um lado, uma verdade processual, estabelecida no processo por meio das provas e pelos procedimentos probatórios e, por outro lado, a verdade material, histórica, insuscetível de ser alcançada pelas provas judiciais. No entanto, como bem observou o autor, essa distinção é inaceitável, vez que parece insustentável a ideia de uma verdade judicial totalmente distinta e autônoma da verdade ocorrida no espaço e no tempo.

Ademais, ainda que a obtenção da verdade possa ser limitada por diversos fatores, não se poderia conceber uma sentença justa que não estivesse amparada pela preocupação de uma verificação correta dos fatos. ${ }^{15}$

O segundo tipo de razões para a problemática que envolve a prova e a verdade dos fatos, conforme Taruffo, se refere ao lugar que se atribui à verdade na teoria do processo. É comum encontrar teorias que resolvem o impasse simplesmente afirmando que não é objetivo do processo a busca da verdade, visto que seu objetivo seria simplesmente a resolução das controvérsias e não a produção de decisões verdadeiras. Porém, como o próprio autor observa, essa constatação leva a uma contradição entre a teoria da prova e a teoria do processo. A primeira estabelece que a função da prova consiste em estabelecer a verdade dos fatos, enquanto a segunda diz, ao contrário, que a função do processo não consiste, em absoluto, na determinação da verdade dos fatos. Resta inexplicado, assim, para que servem as provas no processo, já que estas estão dirigidas a produzir resultados nos quais o processo não estaria interessado. ${ }^{16}$

Parece equivocado afirmar que o processo não estaria interessado na determinação da verdade dos fatos, até porque, mesmo que se conceba o processo como instrumento para resolver conflitos, essa resolução não seria justa enquanto totalmente

\footnotetext{
14 TARUFFO, Michele. La prueba de los hechos. Madrid: Trotta, 2005, p. 24.

15 GOMES FILHO, Antônio Magalhães. Direito à Prova no Processo Penal. São Paulo: Revista dos Tribunais, 1997, p. 54.

16 TARUFFO, Michele. op. cit., p. 25-26.
} 
Revista Eletrônica de Direito Processual - REDP. Volume 15. Janeiro a Junho de 2015 Periódico Semestral da Pós-Graduação Stricto Sensu em Direito Processual da UERJ. Patrono: José Carlos Barbosa Moreira. www.redp.com.br ISSN 1982-7636 PP 349-376

dissociada da verdade histórica.

É claro que, como já asseverou Greco, uma das maiores ilusões que a consciência democrática contemporânea pode difundir na sociedade é a de que, no Estado de Direito, todo aquele que tiver um direito lesado ou ameaçado receberá do Estado a mais ampla e eficaz tutela jurisdicional apta a lhe assegurar o seu pleno gozo. Isso porque, apesar de ser certo que o direito nasce dos fatos, até hoje não houve nenhuma ciência ou saber humano que fosse capaz de empreender sua reconstrução de forma absolutamente segura e aceita por todos, para que o juiz pudesse se limitar a dizer o direito aplicável. ${ }^{17}$

No entanto, uma decisão judicial que se pretende por justa - e é certo que a justiça das decisões é um valor a ser tutelado em um Estado Democrático de Direito deve estar inequivocamente assentada em pressupostos fáticos verdadeiros, o que, por sua vez, depende de uma atividade adequada de reconstrução dos fatos.

Por outro lado, também não se pode conformar com a ideia amplamente difundida de que no processo civil contenta-se com a verdade formal, enquanto no processo penal exige-se a verdade real, como se existisse mais de uma verdade. A verdade é única, não admite graduações. O que difere o processo civil do processo penal, acima de tudo, é o grau de convicção exigido para uma decisão condenatória, já que no último há a necessidade de se desconstruir a presunção de inocência do acusado. Além do mais, no Processo Civil, tratando-se em grande parte de direitos disponíveis, o juiz pode construir esse convencimento a partir de presunções.

Ademais, a caracterização da verdade como "real", no processo penal, traz em seu âmago uma trajetória histórica de opressões e arbítrios na busca da prova. Conforme aponta Aury Lopes $\mathrm{Jr}^{18}{ }^{18}$ com o apoio de Perfecto Ibáñez, está demonstrado empiricamente que o processo penal, sempre que buscou uma verdade mais material e consistente, e com menos limites na atividade de busca, produziu uma verdade de menor qualidade e com pior trato para o imputado. Se, por um lado, o sistema inquisitório admite um substancialismo e uma relativização da garantia da forma em nome da verdade real, de outro, o modelo acusatório pauta-se por um formalismo protetor, respeitando a forma enquanto valor. ${ }^{19}$

\footnotetext{
${ }^{17}$ GRECO, Leonardo. O Conceito de Prova. In: Revista da Faculdade de Direito de Campos. Anos IV e V, no 4-5. Campos dos Goytacazes: FDC, 2003-2004, p. 213.

${ }^{18}$ LOPES JR., Aury. Direito Processual Penal. 10 ${ }^{\mathrm{a}}$ ed. São Paulo: Saraiva, 2013, p. 566.

${ }^{19}$ Idem, p. 545.
} 
Revista Eletrônica de Direito Processual - REDP. Volume 15. Janeiro a Junho de 2015 Periódico Semestral da Pós-Graduação Stricto Sensu em Direito Processual da UERJ. Patrono: José Carlos Barbosa Moreira. www.redp.com.br ISSN 1982-7636 PP 349-376

E, nesse ponto, as garantias fundamentais do processo são as regras necessárias a serem respeitadas para que o processo se desenvolva com absoluto respeito à dignidade humana, de modo que "a justiça de seu resultado esteja assegurada pela adoção das regras mais propícias à ampla e equilibrada participação dos interessados, à isenta e adequada cognição do juiz e à apuração da verdade objetiva: um meio justo para um fim justo." 20

\section{A Garantia da Motivação das Decisões Judiciais à luz do Processo Justo}

Da noção de processo justo emana o dever de motivação das decisões judiciais, embora tal exigência não se mostre expressa nos textos das Convenções Europeia e Americana de Direitos Humanos.

Conforme Serge Guinchard ${ }^{21}$, a motivação é indispensável à qualidade da justiça, constituindo-se em uma muralha contra a arbitrariedade, além de forçar o juiz a tomar consciência de sua opinião, de seu alcance. Ainda segundo o autor, ela fornece ao litigante uma justificação da decisão e tem o condão de proporcionar uma análise científica da jurisprudência, além de permitir ao tribunal superior a realização de seu controle.

Como aponta Barbosa Moreira ${ }^{22}$, foi a partir da segunda metade do século XVIII que se começou a generalizar, nas legislações ocidentais, a exigência feita aos juízes de declarar, em seus pronunciamentos decisórios, as razões em que se baseavam. No entanto, conforme o autor, a história registra precedentes mais antigos de decisões que precisavam ou costumavam ser motivadas. Nesse sentido, Taruffo indica que desde o último período do Império Romano existiam sentenças motivadas, isto é, os juízes dos séculos VII e VIII motivavam suas resoluções escrevendo em perfeito latim as razões da decisão. $^{23}$

No século XIX, a motivação das decisões judiciais passou a ser traço comum a quase todas as codificações processuais europeias, tendo sido a tendência iniciada a partir da lei de 1790 na França, pela qual os legisladores destroem o sistema judicial

\footnotetext{
${ }^{20}$ GRECO, Leonardo. op. cit., p. 225.

${ }^{21}$ GUINCHARD, Serge. et. al. Droit Processuel - Droits Fondamentaux du Procès. $7^{\mathrm{a}}$ ed. Paris: Dalloz, 2013, p. 1.068-1.069.

${ }^{22}$ BARBOSA MOREIRA, José Carlos. op. cit., p. 83.

23 TARUFFO, Michele. La Motivación de La Decisión sobre los Hechos. In: Proceso y Decisión. Lecciones Mexicanas de Derecho Procesal. Madrid: Marcial Pons, 2012, p. 87.
} 
Revista Eletrônica de Direito Processual - REDP. Volume 15. Janeiro a Junho de 2015 Periódico Semestral da Pós-Graduação Stricto Sensu em Direito Processual da UERJ. Patrono: José Carlos Barbosa Moreira. www.redp.com.br ISSN 1982-7636 PP 349-376 prevalecente e impõem a obrigação de motivação. ${ }^{24}$

Ocorre que, a despeito de a obrigação de motivação já estar incluída no bojo da maioria das codificações ocidentais, foi com o segundo pós-guerra que a questão ganha maior relevo, através do movimento de constitucionalização das garantias do processo, especialmente, do dever de fundamentar. Assim, destaca-se a Constituição italiana de 1948, a primeira a se mover nesta direção, que no seu artigo 111 consagra a garantia. Seguindo a tendência, também inseriram tal mandamento Portugal, no artigo 205 da Constituição de 1976; Espanha, no artigo 120 da Constituição de 1978; Bélgica, no artigo 149 da Constituição de 1994. No Brasil, a Constituição de 1988 contempla a fundamentação das decisões judiciais no artigo 93, IX, juntamente com a publicidade, garantias inerentes à jurisdição.

Esse movimento de constitucionalização dos princípios de administração da justiça se relaciona com o contexto histórico da queda de regimes totalitários e autoritários e a consequente redemocratização, permitindo que se considere a garantia da motivação das decisões como um marco fundamental de ruptura com a arbitrariedade rumo a uma forma de exercício de poder que encontra sua legitimação na prestação de contas de seu modo de atuar.

Conforme Moacyr Amaral Santos, ainda cumpre grifar-se o fundamento político da motivação, qual seja, a necessidade que têm os decretos judiciais de serem fundamentados para que a consciência pública admita a legitimidade da justiça por eles proferida. ${ }^{25}$ Nesse sentido, Gomes Filho, ressalta a transformação na concepção do papel do juiz nas últimas décadas, que deixou de ser mero aplicador de regras estabelecidas pelo legislativo e passou a exercer funções de importante ator político. Isso porque, na visão do autor,

como uma espécie de prestação de contas desse modo de atuar, a motivação das decisões judiciais adquire uma concepção que transcende o âmbito próprio do processo para situar-se no plano mais elevado da política, caracterizando-se como o instrumento mais adequado ao controle sobre a forma pela qual se exerce a

\footnotetext{
${ }^{24}$ Idem, p. 88.

25 AMARAL SANTOS, Moacyr. Prova Judiciária no Cível e Comercial. vol. I, 2a ed., São Paulo: Max Limonad, 1952, p. 439.
} 
Revista Eletrônica de Direito Processual - REDP. Volume 15. Janeiro a Junho de 2015

Periódico Semestral da Pós-Graduação Stricto Sensu em Direito Processual da UERJ.

Patrono: José Carlos Barbosa Moreira. www.redp.com.br ISSN 1982-7636 PP 349-376

função judiciária. ${ }^{26}$

Assim, pode-se dizer com esteio em Taruffo que o poder autoritário tal como o entenderam muito bem os teóricos do processo canônico é aquele em que não se explica aos destinatários de seu exercício as razões das decisões. A autoridade de uma decisão repousa sobre a falta de justificação de modo que, quanto mais poder ostente sem dizer absolutamente nada, então será mais forte o poder e, com isso, mais autoridade terão as decisões tomadas. ${ }^{27}$

Paralelamente o Estado de direito, segundo Brüggemann, é o Estado que se justifica. A decisão judicial, conforme Barbosa Moreira, constitui um ato emanado de um dos poderes públicos e destinado a influir na vida de dois ou mais membros da coletividade. Sendo assim, o Estado de Direito não está autorizado a interferir em nossa esfera pessoal sem justificar sua interferência. ${ }^{28}$

Nesse contexto, a legitimação democrática dos membros do Judiciário não resulta de investidura no cargo por eleição, mas deriva do modo pelo qual a função jurisdicional é exercida ${ }^{29}$. Como salienta Ennio Amodio, "em nosso regime democrático, a obrigação de motivação torna-se o meio pelo qual o sujeito investido no poder jurisdicional, membro do aparato instrumental da vontade popular, presta contas da própria atuação à fonte de que deriva a sua investidura." 30

$\mathrm{Na}$ sociedade contemporânea é desejável que as decisões sejam legítimas, dotadas de autoridade, mas, sobretudo, que sejam decisões justificadas. A responsabilidade do juiz converteu-se na responsabilidade de justificar as suas decisões, expondo as razões pelas quais se chegou a tal posicionamento. Sendo assim, a base para o uso do poder e da autoridade reside mais na aceitação das decisões judiciais do que na forma de poder que possam ter os juízes. Paralelamente, o exercício concreto do poder

\footnotetext{
${ }^{26}$ GOMES FILHO, Antônio Magalhães. A garantia da motivação das decisões judiciais na Constituição de 1988. In: Processo Penal e Democracia: estudos em homenagem aos 20 anos da Constituição da República de 1988. Rio de Janeiro: Lúmen Júris, 2009. p. 59-60

${ }^{27}$ TARUFFO, Michele. La Motivación de la decisión... cit., p. 90.

${ }^{28}$ BARBOSA MOREIRA, José Carlos. Prueba y motivación de la sentencia. In: Temas de Direito Processual: oitava série. São Paulo: Saraiva, 2004, p. 107.

${ }^{29}$ GOMES FILHO, Antônio Magalhães. op. cit., p. 60.

${ }^{30}$ Tradução livre. No original: "Nel nostro regime democratico l'obbligo di motivazione diventa allora il mezzo mediante il quale i soggetti investiti del potere giurisdizionale, membri dell'apparatto strumentale della volontá popolare, rendono conto del proprio operato alla fonte da cui deriva la loro investitura." AMODIO, Ennio. Motivazione della sentenza penale. In: Enciclopedia del Diritto. Milano: Giuffrè, 1977, p. 188.
} 
Revista Eletrônica de Direito Processual - REDP. Volume 15. Janeiro a Junho de 2015 Periódico Semestral da Pós-Graduação Stricto Sensu em Direito Processual da UERJ. Patrono: José Carlos Barbosa Moreira. www.redp.com.br ISSN 1982-7636 PP 349-376

jurisdicional efetua-se através de um procedimento que culmina em uma decisão fundamentada em argumentos racionalizados. Essa especial condição identifica, individualiza e contrapõe o poder jurisdicional aos demais poderes, cuja legitimação política e de exercício decorre diretamente da vontade da maioria. ${ }^{31}$

A motivação tem ainda relevância como garantia de efetividade dos direitos fundamentais que, segundo Gomes Filho, devem determinar a direção das decisões jurisdicionais. Assim, a motivação serve, por um lado, para verificar - através do acompanhamento do raciocínio desenvolvido pelo juiz para chegar a um provimento restritivo daqueles direitos - se foram efetivamente obedecidas as regras do devido processo; por outro, será igualmente por intermédio da fundamentação que será viável constatar se a decisão aplicou validamente as normas que permitiam a restrição e se foi apreciado, de maneira correta, o contexto fático que a autorizava. ${ }^{32}$ Conforme Greco, todo provimento jurisdicional deve ser motivado, apresentando justificação suficiente do seu conteúdo e evidenciando o respeito ao contraditório participativo através do exame e consideração de todas as alegações e provas pertinentes apresentadas pelas partes. ${ }^{33}$

Nesse contexto, Ferrajoli ${ }^{34}$ atribui à motivação a qualidade de garantia de segundo grau ou garantia das garantias, pois representa um instrumento de controle sobre a efetividade das demais garantias processuais. Desta forma, através da decisão motivada, é possível verificar se o juiz decidiu com imparcialidade, se foi garantida a ampla defesa, se o contraditório foi rigorosamente observado, principalmente enquanto direito de influência, além da paridade de armas. Essas duas últimas importantes garantias impõem que as partes sejam capazes de, em igualdade de condições, influir eficazmente na formação do convencimento do juiz. Segundo Trocker, ${ }^{35}$ o juiz não age em causa própria, e a sua decisão é um ato que nasce do diálogo entre as partes e com as partes, que são seus destinatários.

Ferrajoli ainda aponta que a motivação da sentença penal

exprime e ao mesmo tempo garante a natureza cognitiva em vez

\footnotetext{
${ }^{31}$ LOPES, José Antônio Mouraz. A Fundamentação da Sentença no Sistema Penal Português: legitimar, diferenciar, simplificar. Coimbra: Almedina, 2011, p. 56 e 61.

32 GOMES FILHO, Antônio Magalhães. op. cit., p. 61-62.

${ }^{33}$ GRECO, Leonardo. Garantias Fundamentais... cit.

34 FERRAJOLI, Luigi. Direito e Razão: teoria do garantismo penal. $2^{\mathrm{a}}$ ed. São Paulo: Revista dos Tribunais, 2006, p. 567.

${ }^{35}$ TROCKER, Nicoló. apud. GOMES FILHO, Antônio Magalhães. op. cit., p. 60.
} 
Revista Eletrônica de Direito Processual - REDP. Volume 15. Janeiro a Junho de 2015

Periódico Semestral da Pós-Graduação Stricto Sensu em Direito Processual da UERJ. Patrono: José Carlos Barbosa Moreira. www.redp.com.br ISSN 1982-7636 PP 349-376

da natureza potestativa do juízo, vinculando-o, em direito, à estrita legalidade, e, de fato, à prova das hipóteses acusatórias. É por força da motivação que as decisões judiciárias resultam apoiadas, e, portanto, legitimadas, por asserções, enquanto tais verificáveis e falsificáveis ainda que de forma aproximada; que a "validade" das sentenças resulta condicionada à "verdade", ainda que relativa, de seus argumentos; que, por fim, o poder jurisdicional não é o "poder desumano" puramente potestativo da justiça de cádi, mas é fundado no "saber", ainda que só opinativo e provável, mas exatamente por isso refutável e controlável tanto pelo imputado e sua defesa como pela sociedade. ${ }^{36}$

O ponto final da fala de Ferrajoli acima transcrita é interessante por deixar clara as funções endoprocessual e extraprocessual da motivação, de que faz menção Taruffo $^{37}$.

Pela função endoprocessual o objetivo seria essencialmente facilitar a caracterização dos defeitos da decisão que podem ensejar a sua impugnação e definir e individualizar o conteúdo e o alcance da mesma, como instrumento interpretativo do dispositivo da sentença. Como observa Humberto Dalla, a motivação permite às partes controlar se as razões e provas por elas apresentadas foram realmente levadas em consideração pelo juiz na decisão ${ }^{38}$. Estas devem poder compreender e controlar eventuais erros de valoração através de recurso ao tribunal superior que, por sua vez, deverá estar em condições de exprimir um juízo concordante ou divergente sobre a decisão proferida.

Por outro lado, no aspecto extraprocessual, a motivação visa garantir a transparência do processo decisório, permitindo um controle externo por parte de qualquer pessoa, isto é, da opinião pública, como expressão do regime democrático no

\footnotetext{
${ }^{36}$ FERRAJOLI, Luigi. op. cit., p. 573-574.

${ }^{37}$ Sobre as funções endo e extraprocessual da motivação, ver: TARUFFO, Michele. La Motivación de la Decisión... cit., p. 90 e 91. Também em ___. La Motivación de la Sentencia Civil. Trad. Lorenzo Córdova Vianello. Madrid: Editorial Trotta, 2011, 335 e ss, bem como em: . Considerazioni su prova e motivazione. In: Revista de Processo. Ano 32. n. 151. São Paulo: Revista dos Tribunais, 2007, p. 237.

${ }^{38}$ PINHO, Humberto Dalla Bernardina de. Direito Processual Civil Contemportâneo. $3^{a}$ ed. São Paulo: Saraiva, 2013, v. 1, p. 105.
} 
Revista Eletrônica de Direito Processual - REDP. Volume 15. Janeiro a Junho de 2015

Periódico Semestral da Pós-Graduação Stricto Sensu em Direito Processual da UERJ.

Patrono: José Carlos Barbosa Moreira. www.redp.com.br ISSN 1982-7636 PP 349-376

que se refere à administração da justiça. Como esclarece Taruffo,

à tradicional função endoprocessual, segundo a qual a motivação da sentença tem como objetivo facilitar a impugnação e o juízo sobre a impugnação, acrescenta-se uma função extraprocessual: a motivação representa a garantia da controlabilidade do exercício do poder jurisdicional fora do contexto processual por qualquer pessoa e pela opinião pública em geral. Isso deriva de uma concepção democrática do poder, segundo a qual o exercício do poder deve sempre permitir um controle externo ${ }^{39}$.

Analisando a garantia de motivação das decisões judiciais no sistema português, Mouraz Lopes identifica que a mesma se encontra concretizada de uma forma sólida e autônoma em três importantes dimensões. A primeira se encontra no plano do direito a um processo equitativo, no qual a garantia se insere como direito fundamental devido ao cidadão. Em segundo lugar, o dever de fundamentação, como imposição constitucional no âmbito da tutela jurisdicional, é um dever atribuído aos órgãos judiciais. Por fim, através do trajeto constitucional de densificação da matéria da fundamentação das decisões, emerge uma terceira e mais relevante dimensão constitucional do princípio, qual seja, a fundamentação das decisões como núcleo do princípio da jurisdição. Com apoio em Canotilho, o autor compreende a fundamentação das decisões judiciais como um princípio estruturante do Poder Judicial, de índole jurídico-organizatório e funcional. ${ }^{40}$ Nesse sentido, o princípio constitucional da exigência de motivação nas decisões judiciais deve ser considerado como um elemento fundamental do conceito de jurisdição.

Por outro lado, faz-se importante a análise do que seja uma motivação adequada e suficiente, bem como os parâmetros a serem adotados para avaliar sua racionalidade intrínseca, relacionada ao processo de decisão.

\footnotetext{
39 Tradução livre. No original: "Alla tradizionale funzione endoprocessuale, secondo la quale la motivazione della sentenza è finalizzata a facilitare l'impugnazione e il giudizio sull'impugnazione, si è infatti la garanzia della controllabilità dell'esercizio del potere giudiziario al di fuori del contesto processuale, e quindi da parte del quivis de populo e dell'opinione pubblica in generale. Ciò discende da una concezione democratica del potere, secondo la quale l'esercizio del potere deve sempre poter essere controllato dall'esterno." TARUFFO, Michele. Considerazioni su prova e motivazione. In: Revista de Processo. Ano 32. n. 151. São Paulo: Revista dos Tribunais, 2007, p. 237.

${ }^{40}$ LOPES, José António Mouraz. op. cit., p. 89.
} 
Revista Eletrônica de Direito Processual - REDP. Volume 15. Janeiro a Junho de 2015 Periódico Semestral da Pós-Graduação Stricto Sensu em Direito Processual da UERJ. Patrono: José Carlos Barbosa Moreira. www.redp.com.br ISSN 1982-7636 PP 349-376

Neste particular, duas advertências são formuladas por Taruffo acerca do que não se deve compreender em uma concepção adequada de motivação. Em primeiro lugar, esta não deve se configurar num discurso meramente retórico destinado a persuadir e convencer os destinatários da decisão. O juiz não tem como objetivo persuadir ninguém, apenas demonstrar que a decisão fora tomada baseada em raciocínios lógicos e corretos. Da mesma forma, nem uma demonstração matemática, como tampouco a lógica requer ser persuasiva, simplesmente é válida ou não é, é correta ou não, independentemente de ser persuasiva ou não. Visto assim, a dimensão retórica do discurso não serve para nada. ${ }^{41}$

A outra advertência de Taruffo é no sentido de que a fundamentação não significa prestar contas da forma pela qual o juiz chegou à referida decisão, através da explicitação de todo o processo mental decisório nesse sentido. Como explica o autor, esse processo decisório se constrói, talvez, a partir da primeira folheada dos autos, com a leitura do primeiro ato do processo, e não nos últimos cinco minutos antes da prolação da sentença. ${ }^{42}$ Sendo assim, a motivação é a justificação da decisão, podendo ser definida da seguinte forma:

se trata de un argumento de justificación, de un razonamiento cuyo objetivo es el de proporcionar las razones racionales sobre las cuales la decisión del juez resulta objetivamente aceptable a la luz de los criterios de valoración y de juicio que se aplican en términos generales, para establecer si una verdad determinada tiene fundamento sobre la información disponible y también para precisar si una interpretación determinada de la norma de Derecho es correcta o no. ${ }^{43}$

Seguindo a visão democrática de exercício do poder, subjaz a necessidade de que o conteúdo da motivação seja completo, o que pode ser representado em uma dupla dimensão: por um lado, todas as questões da decisão devem ter, sem exceção, uma correspondente justificação, e, por outro, não são toleráveis exceções à obrigação de motivação em razão dos diferentes tipos de julgamento previstos pelo legislador

\footnotetext{
${ }^{41}$ TARUFFO, Michele. La Motivación de la decisión... cit., p. 93.

${ }^{42}$ Idem, p. 93-94.

${ }^{43}$ Idem, p. 97.
} 
Revista Eletrônica de Direito Processual - REDP. Volume 15. Janeiro a Junho de 2015 Periódico Semestral da Pós-Graduação Stricto Sensu em Direito Processual da UERJ. Patrono: José Carlos Barbosa Moreira. www.redp.com.br ISSN 1982-7636 PP 349-376 ordinário. $^{44}$

Além disso, esse ideal de completude se relaciona com a dimensão extraprocessual da fundamentação, na medida em que a decisão, para ser controlável pelos cidadãos - que não têm acesso a todo o conteúdo do processo, deve ser um texto autossuficiente que contemple todos os requisitos para sua integral compreensão. Assim, todas as questões suscitadas durante o processo e que serão objeto de análise judicial devem estar refletidas na fundamentação.

Não se trata, no entanto, de afirmar a necessidade de uma extensa, detalhada e minuciosa argumentação, mas de garantir o esgotamento dos aspectos fundamentais tratados na decisão relativos à matéria de fato e às questões jurídicas que, nesse sentido, devem ser todos justificados. ${ }^{45}$

De acordo com Greco:

o juiz tem o dever de demonstrar que examinou todos os argumentos relevantes de fato e de direito apresentados pelas partes, porque somente assim terão estas a certeza de que o contraditório participativo foi respeitado, ou seja, de que o juiz efetivamente considerou toda a atividade desenvolvida pelas partes para influir na sua decisão. Não é certo dizer que uma fundamentação racionalmente consistente atende à exigência de motivação. Isso não basta. É preciso demonstrar que todas as alegações, fatos e provas potencialmente relevantes foram examinados. $^{46}$

Acerca da completude da motivação, Taruffo observa sua necessidade para que seja possível o controle tanto processual como extraprocessual em relação à justificação da decisão. Importa ademais, segundo o autor, definir o que significa uma motivação completa. Quando se está em foco a decisão sobre os fatos, seriam três as exigências fundamentais.

A primeira delas é a necessidade de o juiz trazer para o âmbito da motivação todos os fatos juridicamente relevantes para a decisão, tanto os principais, sobre os

\footnotetext{
${ }^{44}$ LOPES, José António Mouraz. op. cit., p. 97.

${ }^{45}$ Idem, p. 98.

${ }^{46}$ GRECO, Leonardo. As garantias fundamentais... cit.
} 
Revista Eletrônica de Direito Processual - REDP. Volume 15. Janeiro a Junho de 2015 Periódico Semestral da Pós-Graduação Stricto Sensu em Direito Processual da UERJ. Patrono: José Carlos Barbosa Moreira. www.redp.com.br ISSN 1982-7636 PP 349-376 quais se fundamenta o direito, como os secundários, como são os indícios, as fontes de presunções, bem como todos as circunstâncias que estão ao redor e que se mostrem relevantes sob o ponto de vista lógico para a decisão. ${ }^{47}$

Em segundo lugar repousa a exigência de que o juiz expresse na fundamentação todas as provas relativas a cada um dos fatos, não somente as que servem para apoiar a decisão judicial, mas também aquelas contrárias à hipótese considerada verdadeira. ${ }^{48} \mathrm{Na}$ verdade, como expressão do contraditório, sobretudo as provas contrárias à hipótese fática constante na sentença devem estar presentes na fundamentação, juntamente com os motivos pelos quais o juiz as rechaçou em favor das demais. Do contrário o juiz poderia acabar incidindo no que Franco Cordero define como "primato dell'ipotesi sui fatti" ${ }^{49}$, em que o juiz cria uma hipótese mental para, então, buscar elementos que venham a comprovar uma decisão já tomada e, em contrapartida, acabaria por ignorar os elementos de prova que levariam a conclusões opostas. Se assim for, claramente o raciocínio será errôneo, considerando que o juiz deixaria de mostrar o motivo pelo qual não levou em consideração as evidências contrárias, visto que estas poderiam ser as decisivas.

Finalmente, o terceiro aspecto que deve se fazer presente em uma concepção de completude da motivação são as justificações dos juízos de valor formulados e que condicionaram a forma na qual o juiz tomou sua decisão. Segundo Taruffo, os juízos de valor podem ser justificados a partir da explicitação do critério de valoração utilizado e, sobretudo, pela demonstração das diversas ponderações que derivam desses critérios, como sua consequência lógica. ${ }^{50}$

\section{A Garantia da Motivação à luz da Jurisprudência da Corte Europeia de Direitos}

\section{Humanos}

As considerações acima expostas acerca dos parâmetros dentro dos quais deve a motivação se situar para que cumpra com as importantes funções também já tratadas, feitas com apoio, principalmente, nas lições de Taruffo, são circunstâncias ideais e

\footnotetext{
47 TARUFFO, Michele. La Motivación de la Decisión... cit., p. 100-101.

${ }^{48}$ Idem, ibidem.

${ }^{49}$ CORDERO, Franco. Guida alla Procedura Penale. Torino: Utet, 1986, p. 51

${ }^{50}$ TARUFFO, Michele. La Motivación de la Decisión... cit., p. 102-103.
} 
Revista Eletrônica de Direito Processual - REDP. Volume 15. Janeiro a Junho de 2015 Periódico Semestral da Pós-Graduação Stricto Sensu em Direito Processual da UERJ. Patrono: José Carlos Barbosa Moreira. www.redp.com.br ISSN 1982-7636 PP 349-376 talvez um pouco afastadas do que realmente a prática acaba por revelar. ${ }^{51}$ Para isso, visando realizar um diagnóstico mais concreto, ou, em outras palavras, visando apresentar um apanhado das condições mínimas exigidas para a conformação da garantia da motivação das decisões judiciais ao contexto do processo justo, nada mais adequado do que analisar a jurisprudência das Cortes Internacionais de Direitos Humanos, mais especificamente a Corte Europeia de Direitos Humanos. A preferência pela Corte europeia tem como justificativa seu mais amplo e detalhado acervo de decisões, o que se deu em virtude da permissão do acesso individual de qualquer cidadão à sua jurisdição, diferentemente da Corte Interamericana, que não possui uma jurisprudência consolidada nessa seara.

A jurisprudência da Corte Europeia desenvolveu algumas aplicações a partir do princípio geral da equidade, que pode ser considerada uma garantia processual autônoma. Essa noção pode permitir sancionar um Estado por um processo não equitativo, mesmo em uma decisão que aparentemente respeita as garantias formais do artigo $6^{\circ}$. A razão é que se leva em conta o objeto e o propósito da Convenção Europeia, no sentido de assegurar efetivamente a garantia de um processo justo. ${ }^{52}$

Nesse sentido, a Corte analisa três critérios principais: 1) É o exame do conjunto do processo que deve ser posto em consideração, no contexto do direito interno. O procedimento deve ser concebido em bloco, de modo que uma aparente violação pode ser compensada em uma etapa posterior, o que descaracteriza a sua ocorrência; 2) A tomada em consideração das aparências é particularmente importante na apreciação da equidade como noção autônoma. É preciso que o respeito às garantias seja aparente; 3) A apreciação em concreto representa uma maior importância para a apreciação de uma noção autônoma. Tudo deve ser verificado concretamente e, além disso, a questão deve ser posta sob o caráter efetivo da equidade do processo. ${ }^{53}$

A exigência de motivação não consta expressamente no texto da Convenção Europeia de Direitos Humanos, mas é considerada garantia implícita no artigo $6^{\circ}$, que traz o direito ao processo justo, em seu parágrafo $1^{\mathrm{o}}$ :

\footnotetext{
51 O próprio Taruffo, ao final de sua exposição acerca do tema em comento faz uma observação pessimista nesse sentido: "Cuando normalmente hablo de estas cosas, sucede que me dicen que tengo muchas pretensiones y que pido que los jueces pierdan su tiempo en redactar motivaciones tan analíticas al tener que considerar absolutamente todo esto que he dicho. Y sí, esto es lo que a mí me gustaría precisamente, soy consciente de que es difícil (...)." In:

52 GUINCHARD, Serge. op. cit., p. 1067.

${ }^{53}$ Idem, p. 1067-1068. . La Motivación de la Decisión... cit., p. 103.
} 
Revista Eletrônica de Direito Processual - REDP. Volume 15. Janeiro a Junho de 2015

Periódico Semestral da Pós-Graduação Stricto Sensu em Direito Processual da UERJ. Patrono: José Carlos Barbosa Moreira. www.redp.com.br ISSN 1982-7636 PP 349-376

Qualquer pessoa tem direito a que a sua causa seja examinada, equitativa e publicamente, num prazo razoável por um tribunal independente e imparcial, estabelecido pela lei, o qual decidirá, quer sobre a determinação dos seus direitos e obrigações de carácter civil, quer sobre o fundamento de qualquer acusação em matéria penal dirigida contra ela. O julgamento deve ser público, mas o acesso à sala de audiências pode ser proibido à imprensa ou ao público durante a totalidade ou parte do processo, quando a bem da moralidade, da ordem pública ou da segurança nacional numa sociedade democrática, quando os interesses de menores ou a proteção da vida privada das partes no processo o exigirem, ou, na medida julgada estritamente necessária pelo tribunal, quando, em circunstâncias especiais, a publicidade pudesse ser prejudicial para os interesses da justiça.

Como exemplo daquele entendimento, pode-se citar as decisões da Corte no caso Van der Hurk contra a Holanda em 19 de abril de 1994: “O artigo 60 obriga as cortes a fundamentar suas decisões, mas não pode ser entendido como requerer uma resposta detalhada para todos os argumentos. ${ }^{54}$ No mesmo sentido, os casos Ruiz Torija contra Espanha e Hiro Balani contra Espanha, ambos de 09 de dezembro de 1994, trazem idêntica observação.

É interessante sublinhar que a Convenção Europeia, em seu artigo 45, estabelece a obrigação de que as decisões proferidas pela própria Corte, seja por meio do Plenário ou pelas Câmaras, sejam fundamentadas.

Não parece haver dúvida, pela análise da jurisprudência da Corte, bem como pela própria Convenção, de que está consagrado no quadro europeu de forma inequívoca a necessidade de motivação das decisões como garantia do direito a ser ouvido por um tribunal imparcial. As decisões do Tribunal mostram que tal exigência, para além de constituir garantia implícita de um processo equitativo, é indispensável para impedir decisões arbitrárias e, nessa medida, constitui elemento indispensável à

\footnotetext{
54 Tradução livre. No original: “Article 6 par. 1 (art. 6-1) obliges courts to give reasons for their decisions, but cannot be understood as requiring a detailed answer to every argument". Disponível em: http://hudoc.echr.coe.int/sites/eng/Pages/search.aspx\#\{"fulltext":["hurk"],"article":["6"],"documentcollect ionid2":["JUDGMENTS"],"itemid":["001-57878"]\}. Acesso em: 06 de novembro de 2014.
} 
Revista Eletrônica de Direito Processual - REDP. Volume 15. Janeiro a Junho de 2015

Periódico Semestral da Pós-Graduação Stricto Sensu em Direito Processual da UERJ.

Patrono: José Carlos Barbosa Moreira. www.redp.com.br ISSN 1982-7636 PP 349-376

qualidade da justiça em um sistema democrático. ${ }^{55}$

Apesar de ter que realizar um trabalho de compatibilização das várias ordens jurídicas distintas dos diversos Estados-membros, cada um com sua cultura, mentalidade e tradição jurídica particular, a Corte procura sempre estabelecer um conteúdo mínimo que deve se fazer presente para assegurar a garantia da motivação no contexto de um processo equitativo, nos termos do artigo $6^{\circ}$.

Desta forma, sublinhou-se, no caso Ruiz Torija contra a Espanha, acima mencionado:

A extensão na qual este dever de fundamentação se aplica pode variar de acordo com a natureza da decisão. Além disso, é necessário ter em conta a diversidade das submissões que um litigante pode trazer perante os tribunais e as diferenças existentes nos Estados contratantes no que diz respeito às disposições legais, normas costumeiras, entendimentos doutrinários e da jurisprudência. Por isso, a questão de saber se o tribunal não cumpriu o dever de fundamentação, decorrente do artigo $6^{\circ}$ da Convenção, só pode ser determinada em função das circunstâncias do caso concreto. ${ }^{56}$

Quanto a esse conteúdo mínimo exigido no modelo de motivação adequado às finalidades da Convenção, a Corte tem expressado que os fundamentos sob os quais repousa a decisão devem ser explicitados com suficiente clareza, como pressuposto do direito das partes de apresentar um recurso. Desta forma, no caso Hadjianastassiou contra a Grécia:

Os Estados Contratantes possuem ampla liberdade na escolha

\footnotetext{
${ }^{55}$ LOPES, José Antônio Mouraz. op cit., p. 114.

56 Tradução livre. No original: "The extent to which this duty to give reasons applies may vary according to the nature of the decision. It is moreover necessary to take into account, inter alia, the diversity of the submissions that a litigant may bring before the courts and the differences existing in the Contracting States with regard to statutory provisions, customary rules, legal opinion and the presentation and drafting of judgments. That is why the question whether a court has failed to fulfil the obligation to state reasons, deriving from Article 6 (art. 6) of the Convention, can only be determined in the light of the circumstances of the case." Disponível em: http://hudoc.echr.coe.int/sites/eng/Pages/search.aspx\#\{"fulltext":["Torija"],"article":["6"],"documentcolle ctionid2":["JUDGMENTS"],"itemid":["001-57909"]\}. Acesso em 06 de novembro de 2014.
} 
Revista Eletrônica de Direito Processual - REDP. Volume 15. Janeiro a Junho de 2015

Periódico Semestral da Pós-Graduação Stricto Sensu em Direito Processual da UERJ. Patrono: José Carlos Barbosa Moreira. www.redp.com.br ISSN 1982-7636 PP 349-376

dos próprios meios para permitir que seus sistemas judiciários respeitem os imperativos do artigo $6^{\circ}$. Os juízes devem, no entanto, indicar com uma suficiente clareza, os motivos sobre os quais eles se baseiam. É assim, por exemplo, que um acusado pode exercer efetivamente um recurso existente. A tarefa da Corte consiste em verificar se o método seguido na questão levou, em um caso determinado, a resultados compatíveis com a Convenção. ${ }^{57}$

No entanto, é imperioso que o tribunal realize um exame adequado das alegações, argumentos e provas apresentados pelas partes, conforme estatuído no caso Boldea contra Romênia, de 15 de fevereiro de $2007^{58}$. É certo que a motivação deve se dar tanto sobre as questões de fato como às de direito, embora a Corte já tenha solidificado o entendimento no sentido da inexigência de uma resposta detalhada a todos os argumentos apresentados pelas partes, como acima fica expresso no trecho colacionado do caso Van der Hurk contra a Holanda em 19 de abril de 1994.

Além disso a Corte asseverou no citado caso Boldea contra Romênia que a noção de processo justo exige do tribunal que tenha somente motivado de forma breve a decisão, seja incorporando as razões fornecidas pelo juiz de primeira instância ou, de outro modo, examinando de fato as questões essenciais que lhe foram apresentadas, que não se contente pura e simplesmente em endossar as conclusões da jurisdição inferior. Importante lembrar que uma fundamentação inexata corresponde a uma não fundamentação na visão da Corte.

O Tribunal Europeu não estabeleceu ainda, entretanto, qualquer formulação positiva que concretize o que se entende por motivação suficiente dentro dos padrões do processo justo.

\footnotetext{
${ }^{57}$ Tradução livre. No original: "Les États contractants jouissent d'une grande liberté dans le choix des moyens propres à permettre à leur système judiciaire de respecter les impératifs de l'article 6 (art. 6). Les juges doivent cependant indiquer avec une clarté suffisante les motifs sur lesquels ils se fondent. C'est ainsi, par exemple, qu'un accusé peut exercer utilement les recours existants. La tâche de la Cour consiste à rechercher si la voie suivie en la matière a conduit, dans un litige déterminé, à des résultats compatibles avec la Convention.” Disponível em: http://hudoc.echr.coe.int/sites/eng/Pages/search.aspx\#\{"fulltext":["motivation"],"sort":["kpdate\% 20Ascending"],"article":["6"],"documentcollectionid2":["GRANDCHAMBER","CHAMBER"],"itemid": ["001-62335"]\}. Acesso em: 06 de novembro de 2014.

${ }^{58}$ Disponível em: http://hudoc.echr.coe.int/sites/eng/Pages/search.aspx\#\{"fulltext":["Boldea\%20v.\%20 Romania"],"languageisocode":["FRA"],"article":["6"],"documentcollectionid2":["JUDGMENTS"],"itemi d":["001-79496"]\}. Acesso em: 06 de novembro de 2014.
} 


\subsection{A Corte Europeia de Direitos Humanos e o Caso Taxquet v. Bélgica}

Quando se fala em motivação das decisões judiciais como pressuposto de um processo justo, é difícil não se questionar acerca da instituição do júri, que historicamente profere vereditos imotivados. Como compatibilizar essa tradicional conformação decisória fundada em meros "sim" e "não", ou, ainda, "culpado" e "inocente" a um contexto de racionalidade e possibilidade de controle proporcionados por uma decisão motivada?

No final de 2010, a Corte Europeia de Direitos Humanos foi invocada a se manifestar no caso Taxquet v. Bélgica acerca de suposta violação do artigo $6^{\circ}$, parágrafo $1^{\mathrm{o}}$ da Convenção Europeia de Direitos Humanos (right to a fair trial), consistente na ausência de razões apresentadas em um julgamento por jurados. Segundo o queixoso, a falta de motivação levou à impossibilidade de compreender os fundamentos que ensejaram a sua condenação.

Diante disso, o até então usual repouso dogmático acerca da matéria teve que dar lugar a um delicado enfrentamento da questão pela Corte, que concluiu pela existência de violação ao processo justo no caso.

Conforme se extrai do acórdão ${ }^{59}$, em 17 de outubro de 2003, Richard Taxquet compareceu perante a Corte Criminal de Liège juntamente com outros sete corréus, acusados pelo homicídio de um ministro de Estado e por uma tentativa de homicídio, tendo sido ambos os crimes supostamente premeditados. Ao final do julgamento, 32 quesitos foram formulados ao júri, quatro dos quais concerniam à participação do demandante nos crimes. Desses, o primeiro questionava a participação no homicídio do ministro, o segundo questionava se havia sido o crime premeditado, o terceiro se referia à tentativa de homicídio e o quarto se esta havia sido premeditada. O júri respondeu afirmativamente aos quatro e em 07 de janeiro de 2004 o demandante foi sentenciado a 20 anos de prisão. Taxquet apelou de sua condenação nas questões de direito, tendo a Corte de Cassação rejeitado o recurso.

A partir da descrição do caso, é possível observar que os quesitos formulados, os mesmos para todos os acusados, foram demasiadamente vagos e imprecisos, contendo

59 Disponível em: http://hudoc.echr.coe.int/sites/eng/pages/search.aspx?i=001-101739. Acesso em $25 / 11 / 2013$. 
Revista Eletrônica de Direito Processual - REDP. Volume 15. Janeiro a Junho de 2015 Periódico Semestral da Pós-Graduação Stricto Sensu em Direito Processual da UERJ. Patrono: José Carlos Barbosa Moreira. www.redp.com.br ISSN 1982-7636 PP 349-376

em um mesmo enunciado várias possíveis interpretações nas quais o júri poderia ter se

filiado. Sendo assim, a partir das respostas positivas dos jurados, não foi possível deduzir qual o entendimento por eles adotado. Além disso, os quesitos não desempenharam a função de nortear o raciocínio dos jurados para chegar a uma decisão justa. $^{60}$

A instituição do Júri subsiste na Bélgica desde a conquista da independência, em 1831, e o Código de Processo Penal estabelece a necessidade de que quesitos sejam formulados aos jurados para o esclarecimento de todas as circunstâncias que podem ter influência nos fatos nos quais se baseou a acusação, circunstâncias estas que devem ter sido discutidas nos procedimentos orais. Esses quesitos podem ser desafiados pelas partes, bem como outros podem ser sugeridos, ficando a decisão a cargo do Tribunal ${ }^{61}$.

Após os quesitos serem entregues aos jurados, juntamente com a acusação escrita e outros documentos, eles se retiram para deliberar de forma privada, apresentando, ao final, as respostas imotivadas, vez que a lei não exige que eles expressem a forma pela qual chegaram ao veredito. No caso de a Corte unanimemente considerar que o júri cometeu um erro substancial, pode-se designar novo julgamento

\footnotetext{
${ }^{60}$ Os quesitos concernentes à participação de Richard Taxquet apresentaram a seguinte redação: "Question 25 - PRINCIPAL COUNT - Is the accused Richard Taxquet, who is present in court, guilty, as principal or joint principal, - either through having perpetrated the offence or having directly cooperated in its perpetration, - or through having, by any act whatsoever, lent such assistance to its perpetration that without it the offence could not have been committed, - or through having, by gifts, promises, threats, abuse of authority or power, scheming or contrivance, directly incited another to commit the offence, - or through having, by means of speeches in a public place or assembly, or by means of any written or printed matter, image or emblem displayed, distributed or sold, offered for sale or exhibited in a place where it could be seen by the public, directly incited another to commit the offence, of having knowingly and intentionally killed [A.C.] in Liège on 18 July 1991? Question 26 - AGGRAVATING CIRCUMSTANCE: Was the intentional homicide referred to in the previous question premeditated? Question 27 - PRINCIPAL COUNT: Is the accused Richard Taxquet, who is present in court, guilty, as principal or joint principal, - either through having perpetrated the offence or having directly cooperated in its perpetration, - or through having, by any act whatsoever, lent such assistance to its perpetration that without it the offence could not have been committed, - or through having, by gifts, promises, threats, abuse of authority or power, scheming or contrivance, directly incited another to commit the offence, - or through having, by means of speeches in a public place or assembly, or by means of any written or printed matter, image or emblem displayed, distributed or sold, offered for sale or exhibited in a place where it could be seen by the public, directly incited another to commit the offence, of having attempted knowingly and intentionally to kill [M.-H.J.] in Liège on 18 July 1991, the intent to commit the offence having been manifested by conduct which objectively constituted the first step towards perpetration of the offence and which was halted or failed to attain the aim pursued only as a result of circumstances outside the control of the perpetrator? Question 28 - AGGRAVATING CIRCUMSTANCE: Was the attempted intentional homicide referred to in the previous question premeditated?" Disponível em: http://hudoc.echr.coe.int/sites/eng/pages/search.aspx?i=001-101739, p. 07-08. Acesso em 25/11/2013. ${ }^{61}$ Idem, p. 10.
} 
Revista Eletrônica de Direito Processual - REDP. Volume 15. Janeiro a Junho de 2015 Periódico Semestral da Pós-Graduação Stricto Sensu em Direito Processual da UERJ. Patrono: José Carlos Barbosa Moreira. www.redp.com.br ISSN 1982-7636 PP 349-376

com novos jurados. No entanto, essa opção foi utilizada em apenas três ocasiões, conforme informações prestadas pelo Governo belga. ${ }^{62}$

Para fundamentar a decisão no caso Taxquet v. Bélgica, a Corte Europeia em sua composição plena realizou uma análise comparada ${ }^{63}$ dos sistemas de Júri adotados pelos Estados-Membros, verificando que as variações entre eles refletem particularidades culturais e históricas. Foi verificado que, em sua forma tradicional, o sistema envolve uma combinação de um número de jurados reunidos com um ou mais juízes profissionais. O número de jurados pode variar de acordo com a matéria em questão e o de juízes varia de país para país. Uma questão comum é que os juízes não podem participar da deliberação dos jurados no que toca ao estabelecimento da culpa, que é de sua exclusiva competência.

Em sete países (Áustria, Bélgica, Irlanda, Noruega, Rússia, Espanha e Suíça), a prática é a submissão aos jurados de um questionário específico sobre as questões de fato antes de sua saída para a deliberação.

Na Irlanda, Inglaterra e Gales, após a conclusão dos debates, o juiz elabora uma síntese do caso para os jurados. Nesta síntese, ele procura chamar a atenção para as provas colhidas e, ao fazê-lo, pode dar indicações sobre a abordagem adequada para tomar em sua valoração. Além do mais, nesse caso, o juiz também fornece aos jurados informações e explanações sobre as normas aplicáveis, sendo esclarecidos também os elementos do crime e estabelecida a cadeia de raciocínio que deve ser seguida pelos jurados para alcançar o veredito.

Em geral, como observou a Corte Europeia, na maioria dos países os jurados deliberam secretamente, podendo o juiz ser chamado excepcionalmente para esclarecer quaisquer questões - a exemplo da Bélgica e da Noruega.

Com exceção da Espanha e Suíça, a regra geral parece ser a de que não seja fornecida motivação para os vereditos na forma tradicional de júri. A Bélgica passou a exigir a motivação após a reforma legislativa de 2009, por influência do caso Taxquet.

A partir dessas observações, restou claro que os Estados membros gozam de liberdade considerável para estabelecer seus sistemas judiciais, desde que estejam de acordo com as exigências do artigo $6^{\circ}$ da Convenção Europeia. A tarefa da Corte consiste em verificar se o método adotado a este fim levou um dado caso concreto a

${ }^{62}$ Idem, p. 10-11.
${ }^{63}$ Idem, p. $15-17$. 
Revista Eletrônica de Direito Processual - REDP. Volume 15. Janeiro a Junho de 2015 Periódico Semestral da Pós-Graduação Stricto Sensu em Direito Processual da UERJ. Patrono: José Carlos Barbosa Moreira. www.redp.com.br ISSN 1982-7636 PP 349-376

resultados compatíveis com os anseios da Convenção. Basicamente, deve-se avaliar se o procedimento considerado em sua totalidade foi justo.

A Corte lembrou dois julgamentos anteriores (R. v. Bélgica e Papon v. França) em que, apesar de não terem sido fornecidas razões para as decisões do júri, o juizpresidente elaborou um questionário preciso dos fatos hábil a compensar as respostas lacônicas dos jurados e de modo a criar um roteiro para que o júri chegasse a uma decisão considerando todos os fatos relevantes. Isso permitiu também ao acusado compreender o veredito acompanhando o raciocínio dos jurados e compensou suficientemente a falta de motivação. Além do mais, as partes puderam desafiar os quesitos propostos e sugerir outros. ${ }^{64}$

O que segue da análise feita é que a Convenção não exige que os jurados fundamentem as decisões. No entanto, para que as exigências do processo justo sejam satisfeitas, o acusado e também o público devem ser aptos a entender o veredito dado, sendo esta uma garantia vital contra arbitrariedades. ${ }^{65}$

As decisões motivadas servem, conforme a Corte, para o propósito de demonstrar às partes que elas foram ouvidas e contribuem para uma maior aceitação da decisão. Por outro lado, elas obrigam os juízes a basear suas razões em argumentos objetivos e preservam os direitos de defesa. Como no caso de tribunais do júri, não há, em regra, obrigação de motivação, deve-se analisar se as garantias do artigo $6^{\circ}$ da Convenção Europeia podem ser acomodadas de outra forma, de modo a evitar qualquer risco de arbitrariedades e para permitir que o acusado entenda as razões para sua condenação. ${ }^{66}$

Essas garantias podem incluir, por exemplo, instruções ou orientações para os jurados dadas pelo juiz-presidente das questões legais envolvidas na prova colhida e, também, inequívocas questões postas aos jurados aptas a formar uma estrutura sobre a qual o veredito se baseará, compensando suficientemente a falta de razões para as respostas dos jurados. Finalmente, deve-se respeitar as vias recursais abertas ao acusado. ${ }^{67}$ No entanto, as meras respostas "sim" e "não" pelos jurados aos quesitos formulados pelo juiz, tendo sido estes formulados de maneira vaga e genérica, podem

\footnotetext{
${ }^{64}$ Idem, p. 24.

${ }^{65}$ Idem, p. 25.

${ }^{66}$ Idem, p. 26

${ }^{67}$ Idem, ibidem.
} 
Revista Eletrônica de Direito Processual - REDP. Volume 15. Janeiro a Junho de 2015 Periódico Semestral da Pós-Graduação Stricto Sensu em Direito Processual da UERJ. Patrono: José Carlos Barbosa Moreira. www.redp.com.br ISSN 1982-7636 PP 349-376 dar a impressão de uma justiça vaga e pouco transparente. ${ }^{68}$

Como se pode observar, a Corte Europeia optou por não desafiar diretamente a instituição do júri, considerando que esta não representaria, em si, uma violação à garantia do processo justo. No entanto é imperioso verificar se, de acordo com a organização dada à instituição do júri pelos Estados membros em âmbito interno podese violar o artigo $6^{\circ}$ da CEDH. A falta de razões para o veredito, em si, não viola a Convenção. No entanto, devem ser satisfeitas algumas garantias mínimas que sirvam ao mesmo propósito e desempenhem a mesma ou similar função que a garantia da motivação.

Trata-se da primeira decisão em que a Corte Europeia explicitamente afirma a importância de se demonstrar os fatos que convenceram o júri da culpabilidade ou inocência do acusado, indicando-se as razões concretas para as respostas dos jurados, de modo a que não só o acusado possa entender o veredito, mas, também, o povo, em nome do qual a decisão é proferida. ${ }^{69}$

\section{CONSIDERAÇÕES FINAIS}

A motivação das decisões judiciais consiste em importante dever que, apesar de não estar expresso no texto da Convenção Europeia de Direitos Humanos, é considerada garantia implícita e indispensável à luz do direito a um processo equitativo, segundo o Tribunal Europeu de Direitos Humanos.

Grande parte das constituições ocidentais vindas com o segundo pós-guerra contemplaram em seus textos a exigência de motivação das decisões, por meio do movimento de constitucionalização das garantias fundamentais do processo. No Brasil, a Constituição Federal de 1988 seguiu a tendência, inserindo tal mandamento no artigo 93, IX.

A motivação cumpre importante papel endoprocessual, no sentido de permitir que as partes compreendam a decisão e possam, inclusive, impugná-la, além de possibilitar a análise pelo tribunal acerca da correção ou não da atividade valorativa do juiz. Por outro lado, se mostra presente também uma função extraprocessual, pela qual o

${ }^{68}$ LOPES, José Antônio Mouraz. Op. cit., p. 117.
${ }^{69}$ Idem, p. 118. 
Revista Eletrônica de Direito Processual - REDP. Volume 15. Janeiro a Junho de 2015 Periódico Semestral da Pós-Graduação Stricto Sensu em Direito Processual da UERJ. Patrono: José Carlos Barbosa Moreira. www.redp.com.br ISSN 1982-7636 PP 349-376

juiz presta contas de seu modo de atuar e o povo toma conhecimento e exerce o controle sobre as decisões judiciais, já que o exercício de poder deve permitir essa fiscalização.

Para que se fixem os parâmetros que norteiam a exigência da motivação, e em que medida esta cumprirá seu papel, a jurisprudência da Corte Europeia de Direitos Humanos pode ser importante aliada, já que bem desenvolvida em relação às garantias fundamentais do processo. Em suma, os modos de satisfazer a essa obrigação podem variar de um Estado para outro, de acordo com os costumes, com disposições de lei, com concepções doutrinárias. O importante é que a motivação atinja um grau de suficiente clareza, especialmente para possibilitar o exercício pela parte do direito de recorrer. $^{70}$

A Corte nunca havia enfrentado, no entanto, a ausência de motivação nos vereditos dos jurados, aceitando, segundo a doutrina, que isto faz da parte do modo como o júri atua, até a decisão Taxquet contra a Bélgica. Nesta oportunidade, o Tribunal reafirmou, de forma enfática, a necessidade da fundamentação concretizar a finalidade endoprocessual subjacente à tutela das garantias do destinatário direto da decisão, mas, sobretudo, atribuiu novo fôlego à tutela da finalidade extraprocessual sustentada na afirmação das razões que devem ser dadas ao povo em nome de quem a decisão é proferida, referentes às razões concretas que convenceram o júri ao seu veredito.

A partir da interpretação realizada pela Corte Europeia de Direitos Humanos no caso Taxquet sobre as decisões imotivadas do Júri, é interessante que cada Estado repense seu próprio modelo de Júri e, se necessário, reflita sobre a necessidade de reforma, uma vez que já se não se sustentam, à luz do direito ao processo justo, as decisões enigmáticas dos jurados, sem qualquer tipo de compreensão sobre os seus fundamentos. É imperioso que se estabeleça uma racionalidade nas decisões do júri, de modo que sejam elas passíveis de controle pelas partes e pela sociedade.

\section{REFERÊNCIAS BIBLIOGRÁFICAS}

AMARAL SANTOS, Moacyr. Prova Judiciária no Cível e Comercial. vol. I, 2a ed., São Paulo: Max Limonad, 1952.

\footnotetext{
${ }^{70}$ Greco, Leonardo. Resenha Informativa sobre o Direito ao Processo Justo na Convenção Europeia e na Convenção Americana dos Direitos do Homem.
} 
Revista Eletrônica de Direito Processual - REDP. Volume 15. Janeiro a Junho de 2015 Periódico Semestral da Pós-Graduação Stricto Sensu em Direito Processual da UERJ. Patrono: José Carlos Barbosa Moreira. www.redp.com.br ISSN 1982-7636 PP 349-376

AMODIO, Ennio. Motivazione della sentenza penale. In: Enciclopedia del Diritto. Milano: Giuffrè, 1977.

BARBOSA MOREIRA, José Carlos. O Juiz e a Prova. In: Revista de Processo. São Paulo, n. 35, p. 178-184, abril/junho de 1984.

. A motivação das decisões judiciais como garantia inerente ao estado de direito. In: Temas de Direito Processual. 2. ed. São Paulo: Saraiva, 1988.

. Prueba y motivación de la sentencia. In: Temas de Direito Processual: oitava série. São Paulo: Saraiva, 2004.

CARNELUTTI, Francesco. Sistema de direito processual civil. $2^{\mathrm{a}}$ Ed. São Paulo: Lemos e Cruz, 2004.

CARVALHO DIAS, Ronaldo Brêtas de; FIORATTO, Débora Carvalho. A Conexão entre os Princípios do Contraditório e da Fundamentação das Decisões na Construção do Estado Democrático de Direito. In: Revista Eletrônica de Direito Processual. Ano 4, Vol. V, Jan./Jun. de 2010.

CHIOVENDA, Giuseppe. Instituições de direito processual civil. Campinas: Bookseller. 2000.

COMOGLIO, Luigi Paolo. Etica e tecnica del "giusto processo". Torino: G. Giappichelli, 2004.

CORDERO, Franco. Guida alla Procedura Penale. Torino: Utet, 1986.

FERRAJOLI, Luigi. Direito e Razão: teoria do garantismo penal. $2^{\mathrm{a}}$ ed. São Paulo: Revista dos Tribunais, 2006.

FISS, Owen. Um Novo Processo Civil: Estudos norte-americanos sobre jurisdição, constituição e sociedade. São Paulo: Editora Revista dos Tribunais, 2004.

GOMES FILHO, Antônio Magalhães. Direito à Prova no Processo Penal. São Paulo: Revista dos Tribunais, 1997.

A garantia da motivação das decisões judiciais na Constituição de 1988. In:

Processo Penal e Democracia: estudos em homenagem aos 20 anos da Constituição da República de 1988. Rio de Janeiro: Lúmen Júris, 2009.

GRECO, Leonardo. Garantias Fundamentais do Processo: O Processo Justo. in Estudos de Direito Processual. Campos dos Goytacazes: Faculdade de Direito de Campos, 2005.

. O Conceito de Prova. In: Revista da Faculdade de Direito de Campos. Anos IV e V, no 4-5. Campos dos Goytacazes: FDC, 2003-2004. 
Revista Eletrônica de Direito Processual - REDP. Volume 15. Janeiro a Junho de 2015 Periódico Semestral da Pós-Graduação Stricto Sensu em Direito Processual da UERJ. Patrono: José Carlos Barbosa Moreira. www.redp.com.br ISSN 1982-7636 PP 349-376 GUINCHARD, Serge. et. al. Droit Processuel - Droits Fondamentaux du Procès. $7^{\mathrm{a}}$ ed. Paris: Dalloz, 2013.

LOPES, José Antônio Mouraz. A Fundamentação da Sentença no Sistema Penal Português: legitimar, diferenciar, simplificar. Coimbra: Almedina, 2011.

LOPES JR., Aury. Direito Procesual Penal. 10ª ed. São Paulo: Saraiva, 2013.

MARINONI, Luiz Guilherme. Teoria Geral do Processo. 2a ed. V. 1. São Paulo: Revista dos Tribunais, 2007.

PINHO, Humberto Dalla Bernardina de. Direito Processual Civil Contemportâneo. $3^{a}$ ed. São Paulo: Saraiva, 2013.

SILVA, Ovídio A. Batista da. Curso de Processo Civil. 3. ed. Porto Alegre: Fabris, 1996.

. Curso de Processo Civil. Vol. 2. 3. ed. São Paulo: Revista dos Tribunais, 1998.

TARUFFO, Michele. La prueba de los hechos. Madrid: Trotta, 2005.

. La Motivación de La Decisión sobre los Hechos. In: Proceso y Decisión.

Lecciones Mexicanas de Derecho Procesal. Madrid: Marcial Pons, 2012.

. La Motivación de la Sentencia Civil. Trad. Lorenzo Córdova Vianello.

Madrid: Editorial Trotta, 2011.

. Considerazioni su prova e motivazione. In: Revista de Processo. Ano 32. n.

151. São Paulo: Revista dos Tribunais, 2007. 